\title{
The importance of long-term genetic monitoring of reintroduced populations: inbreeding in the natterjack toad (Epidalea calamita)
}

\author{
Susanna Phillips ${ }^{1}$, Matthew Geary ${ }^{1}$, Matthew Allmark², Sarah Bennett ${ }^{2}$, Kim Norman³, \\ Rachel J. Ball ${ }^{1}$, Catherine M. Peters ${ }^{1}$ \& Anna P. Muir ${ }^{1}$
}

${ }^{1}$ Conservation Biology Research Group, University of Chester, Chester, CH1 4BJ, UK
${ }^{2}$ Cheshire Wildlife Trust, Bickley Hall Farm, Bickley, Malpas, Cheshire, SY14 8EF, UK
${ }^{3}$ Eni UK Ltd, Liverpool Bay, Point of Ayr, Station Road, Talacre, Flintshire, CH8 9RD, UK

Genetic monitoring is an important, but frequently lacking, component of management actions to support long-term persistence in reintroduced populations. Populations that remain small, due to demographic processes and genetic diversity, are more likely to experience a second extinction event. The natterjack toad (Epidelea calamita) is legally protected in Britain and was the subject of a reintroduction programme in the 1990s. However, subsequent genetic assessment has been mostly lacking. The aim of this study was to assess the genetic diversity of two reintroduced populations of natterjack toads in order to inform conservation management. Adults were sampled and nine microsatellites amplified to assess neutral genetic variation within each site and for comparison with the source population. Inbreeding was observed at the reintroduction sites, as evidenced by high FIS values ( 0.43 and 0.72 ), low observed compared to expected heterozygosities, and significant deviation from Hardy-Weinberg equilibrium. Observed heterozygosity is currently lower in the reintroduction sites than it was in the source population at the time of the reintroductions (Red Rocks: $0.15 \pm 0.20$; Talacre: 0.12 \pm 0.20 ; Ainsdale (source): 0.29). Evidence for a bottleneck was not found, although this is likely a result of sampling overlapping generations. No withinsite population structuring was observed. Such low genetic diversity has not previously been recorded in any natterjack population. Genetic rescue, combined with pool creation, is the most viable option for safeguarding the species at these sites into the future. Our work highlights the importance of ongoing genetic monitoring, in collaboration with conservation organisations, to support conservation management.

Keywords: Reintroduction, amphibian, inbreeding, conservation, natterjack, genetics

\section{INTRODUCTION}

$\mathrm{R}_{\mathrm{o}}^{\mathrm{e}}$ eintroductions, the intentional movement and release of an organism inside its indigenous range from which it has disappeared (IUCN Species Survival Commission, 2013), are an increasingly common conservation intervention (Germano et al., 2015; Taylor et al., 2017; Attard et al., 2016). The use of movement of individuals to sites as a conservation measure is predicted to increase in order to mitigate the effects of climate-change (Germano et al., 2015). The speed and severity of anthropogenically induced environmental change has led to the loss of species and ecosystem function in many areas and the aim of a reintroduction is to re-establish a viable population of the focal species (IUCN Species Survival Commission, 2013; Corlett, 2016). The likelihood of success for species reintroductions is based on environmental, demographic and genetic factors and a broad understanding of the factors that influence a species' persistence is required prior to conservation intervention (Mims et al., 2019). As a result, the majority of scientific evaluation related to reintroductions takes place prior to the movement of individuals, with only $4 \%$ of the reintroduction biology literature addressing population persistence (Taylor et al., 2017). Further research is needed to support ongoing evidence-based conservation management that meets reintroduction goals of establishing long-term viable populations.

Despite their prevalence as a conservation management approach, many reintroduction attempts are unsuccessful (Morell, 2008). Unsuccessful reintroductions, in the short term, can be adversely affected by issues such as failure to properly address the causes of the previous population's decline at a site and maladaptation to a novel environment of source individuals, which impact the population growth rate (Cochran-Biederman et al., 2015; Robert et al., 2015). Over the longer-term, reintroduced populations that remain small, due the interplay of demographic processes and genetic diversity, are more likely to experience a second extinction event ( Robert et al., 2015; Mims et al., 2019). The extinction vortex is a positive feedback loop 


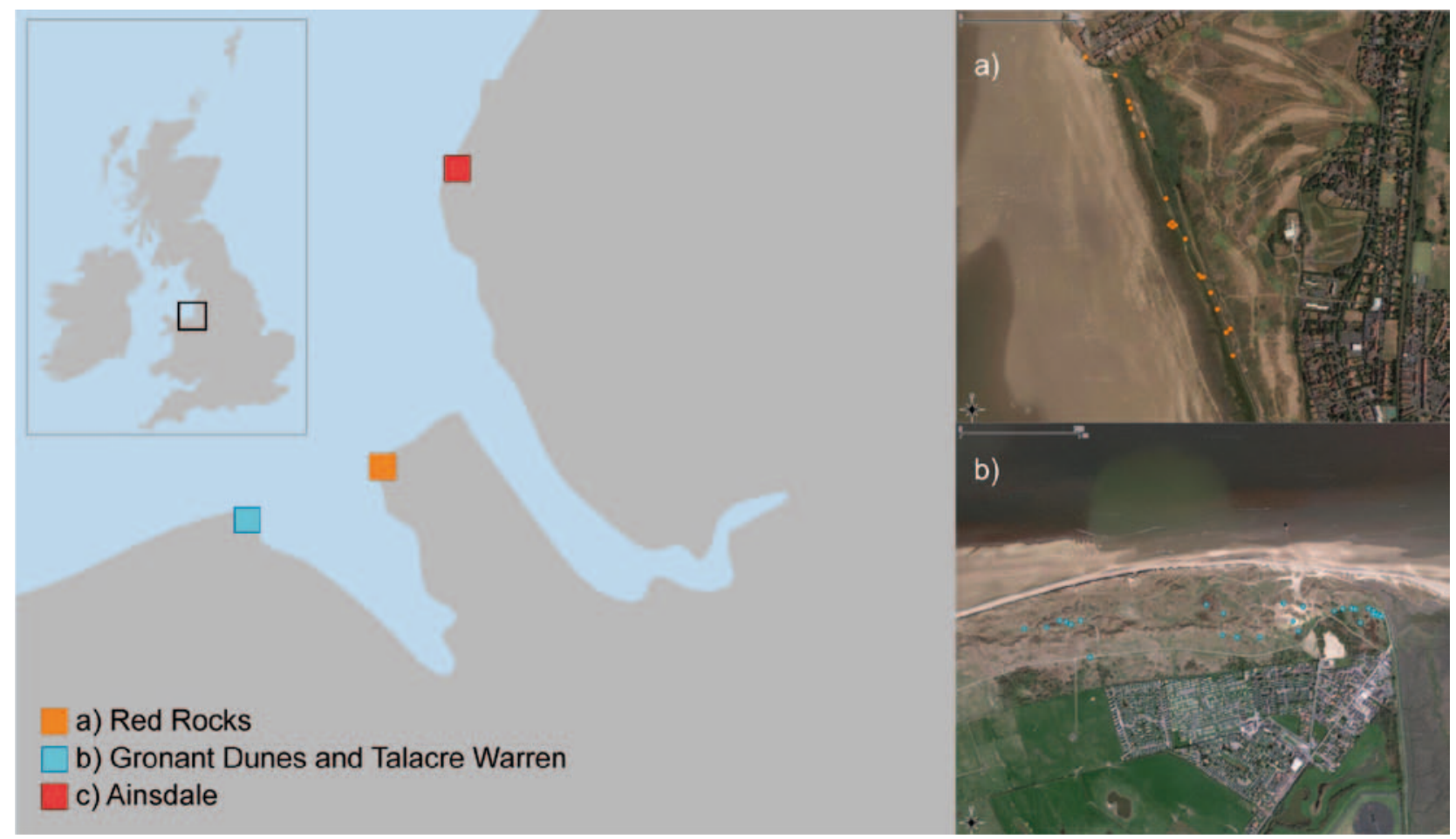

Figure 1. Location of reintroduction study sites, Red Rocks and Gronant Dunes and Talacre Warren, alongside the source site, Ainsdale. Sampling points within the study sites are shown for a) Red Rocks and b) Gronant Dunes and Talacre Warren.

that describes how small, isolated populations are subject to lower genetic diversity and inbreeding, which reduces fitness and reproductive output, thus further reducing population size (Palomares et al., 2012; Allendorf et al., 2013). The effects of the extinction vortex have been identified in a range of taxa from mammals (Palomares et al., 2012), to birds (Blomqvist et al., 2010), to amphibians (Rowe \& Beebee, 2003). The long-term prospects for populations within the extinction vortex are poor and conservation intervention is likely the only way to prevent extinction (Rowe \& Beebee, 2003; Eduardo et al., 2012; Norén et al., 2016). Therefore, genetic monitoring is an important component of management actions to support long-term persistence in reintroduced populations.

The natterjack toad (Epidelea calamita) is an ecological specialist amphibian, found in dune and heathland habitat, that relies on shallow ephemeral pools surrounded by little or no vegetation for breeding and burrowing (Beebee et al., 1996). The species suffered widespread declines in Britain in the early 20th century, due to habitat loss and successional changes at breeding sites (Beebee, 2014). The species is now legally protected in Britain and was the subject of an intensive three year recovery programme in the early 1990s that included reintroductions from nearby extant populations, alongside extensive habitat management (Denton et al., 1997). Early assessments, based on spawn string counts, suggested that at least six reintroductions from across Britain had resulted in expanding populations with eight additional sites showing initial signs of success (Denton et al., 1997). However, preliminary evidence of inbreeding following reintroduction was found at one out of five reintroduction sites assessed (Rowe et al., 1998). Genetic monitoring has only taken place at one reintroduced natterjack population in Britain since that time and only following additional releases to a population showing declines (Beebee, 2014, 2018). As low genetic diversity has been linked to reduced fitness in natterjack larvae (Rowe et al., 1999), it is imperative that genetic assessment of reintroduced populations is used to support management decisions to ensure long-term population survival.

The natterjack toad population along the Merseyside dune system is considered a stronghold for the species within Britain (Rowe et al., 1998; McGrath \& Lorenzen, 2010). Ainsdale, part of the Merseyside dune system, was used as a source site for a number of translocations in the mid-1990s to areas where local natterjack extinctions had taken place (Denton et al., 1997). These reintroduction sites included two Sites of Special Scientific Interest (SSSIs) situated within the Ramsar designated Dee Estuary catchment: Gronant Dunes/Talacre Warren (Wales) and Red Rocks (England). Natterjacks were driven to extinction due to urbanisation and severe habitat fragmentation around 1950 at Gronant Dunes/ Talacre Warren and in the early 1990s at Red Rocks (M. Cartwright, personal communication). Following pond creation in 1995, spawn was translocated from the Ainsdale site to Gronant Dunes/Talacre Warren every year between 1995 and 1998 (Beebee \& Buckley, 2014). At Red Rocks, spawn strings and captive-reared tadpoles were reintroduced to the site from Ainsdale in 1996. At both sites, concerns have been raised by land managers that annual spawn string counts in the last ten years have fluctuated widely. However, toads are known to show population oscillations with long periodicities so identifying population trends from demographic data alone can be misleading (Beebee \& Rowe, 2001). Genetic testing can help distinguish between natural oscillations and low population sizes (Beebee \& Rowe, 2001). Reduced genetic diversity, as a result of low population 
sizes, in reintroduced populations compared to source populations has previously been observed at natterjack reintroduction sites (Rowe et al., 1998). However, genetic monitoring has only been carried out at one natterjack site in the UK in the last twenty years and has never taken place at the reintroduction sites within the Dee Estuary.

Therefore, the aim of this study was to assess the genetic diversity of two reintroduced populations of the natterjack toad in order to inform evidence-based conservation management to support population persistence. In particular, we answered the following questions: 1) What are the levels of neutral genetic diversity within each reintroduction site and how does this compare to previously published levels at the source population?; 2) Have populations experienced a bottleneck and is there evidence of inbreeding at reintroduction sites?; and 3 ) Is gene flow restricted between breeding pools within each site?

\section{MATERIALS AND METHODS}

\section{Sampling}

Natterjack toad samples were collected from two study sites situated within the Ramsar designated Dee Estuary catchment on the north-west coast of Great Britain (Fig. 1). Red Rocks SSSI (11.38 ha) on the Wirral peninsula comprises of sand dune and swamp habitats, particularly reedbed and saltmarsh vegetation, and has been managed as a whole by Cheshire Wildlife Trust since 2014. Gronant Dunes/Talacre Warren SSSI (518.8 ha), herein referred to as Talacre, on the North Wales coastline supports a range of sand dune, shingle, swamp and saltmarsh habitats and, since the early 1990s, has been managed by ENI UK Ltd.

Sample collection took place during the annual natterjack toad census surveys at each site, between March and June 2017. A visual survey method was used to find adult natterjack toads, which involved traversing the area slowly on foot searching for individuals during their hunting period by making conscious low sweeps of a powerful torch beam (Denton \& Beebee, 1992). Each adult toad encountered was handled with a clean set of unpowdered nitrile gloves to prevent possible disease transmission. Buccal swabs, a non-destructive technique for genetic sampling of amphibians (Broquet et al., 2007), were collected from every adult encountered during the census surveys, under an A29 Natural England license. A standard sample size of 30 per site was used, in line with similar studies on genetic variability in natterjack toads (Rowe et al., 1998, 2000a), to sufficiently encompass the genetic diversity of the population (Hale et al., 2012). Geographic location of encounter was recorded for each individual and samples were stored at $-20^{\circ} \mathrm{C}$ prior to DNA extraction.

\section{Molecular methods}

DNA extraction was carried out using a QIAGEN DNeasy Blood and Tissue Kit (Qiagen Inc., Crawley) according to the manufacturer's protocol, with the following alterations. Firstly, incubation was extended to 24 hours to ensure complete lysis. Secondly, swab tips were loaded into QIAshredder homogenizers (Qiagen Inc., Crawley) and centrifuged at 13,000 rpm for two minutes in order to maximise lysate yield. Finally, elution proceeded as a two-step process, adding $30 \mu \mathrm{l}$ Buffer AE that had been heated to $70{ }^{\circ} \mathrm{C}$, incubating at room temperature for five minutes, and centrifuging at 13,000 rpm for two minutes at each step, in order to maximise yield (as per Peters et al., 2019).

Nine microsatellite markers were chosen from those designed for E. calamita by Rowe et al. (1997, 2000b) and divided into three multiplex panels (Table 1). The forward primer of each pair was labelled with the fluorescent dyes (Eurofin Genomics, Ebersberg, Germany): FAM (Blue), ATT550 (Yellow) and Yakima Yellow (Green), to be used with a LIZ-labelled (orange) GS500 size standard. Samples were amplified alongside negative controls by multiplex PCR using QIAGEN Multiplex PCR mixes (Qiagen Inc, Crawley) using the default reagent concentrations recommended by the kit instructions. Touchdown polymerase chain reactions (PCR) were performed as follows (Multiplex A/ Multiplexes B and C): Initial denaturation took place at 94 ${ }^{\circ} \mathrm{C}$ for $5 \mathrm{~min}$, followed by $1 \mathrm{cycle}$ of $94^{\circ} \mathrm{C}$ for $1 \mathrm{~min}, 66^{\circ} \mathrm{C} / 62$ ${ }^{\circ} \mathrm{C}$ for $1 \mathrm{~min}$ and $72{ }^{\circ} \mathrm{C}$ for $1 \mathrm{~min}$; followed by 2 cycles of $94{ }^{\circ} \mathrm{C}$ for $1 \mathrm{~min}, 64{ }^{\circ} \mathrm{C}$ for $1 \mathrm{~min}$ and $72{ }^{\circ} \mathrm{C}$ for $1 \mathrm{~min}$; then 2 cycles of $94^{\circ} \mathrm{C}$ for $1 \mathrm{~min}, 64^{\circ} \mathrm{C} / 60^{\circ} \mathrm{C}$ for $1 \mathrm{~min}$ and 72 ${ }^{\circ} \mathrm{C}$ for $1 \mathrm{~min}$; followed by 2 cycles of $94{ }^{\circ} \mathrm{C}$ for $1 \mathrm{~min}, 60$ ${ }^{\circ} \mathrm{C} / 58{ }^{\circ} \mathrm{C}$ for $1 \mathrm{~min}, 72{ }^{\circ} \mathrm{C}$ for $1 \mathrm{~min}$; then 21 cycles of 94 ${ }^{\circ} \mathrm{C}$ for $1 \mathrm{~min}, 58{ }^{\circ} \mathrm{C} / 55^{\circ} \mathrm{C}$ for $1 \mathrm{~min}$ and $72{ }^{\circ} \mathrm{C}$ for $1 \mathrm{~min}$; with a final extension step of $72^{\circ} \mathrm{C}$ for $5 \mathrm{~min}$. PCR products were separated and visualised using agarose (Thermo Fisher Scientific, Waltham) gel electrophoresis using a BioRad Gel Doc ${ }^{\mathrm{TM}}$ EZ Imager and Image lab 4.0 software (Bio-Rad Laboratories 2017). Amplified samples were subsequently purified using the ExoSAP-IT PCR Product Clean up Reagent (Applied Biosystems, Massachusetts) according to the manufacturer's protocol. PCR products were genotyped on an $A B I 3130 X L$ sequencing machine by Eurofins Genomics and analysed using Peak Scanner v 2.0 (Applied Biosystems, Massachusetts). Ten per cent of samples were re-amplified and genotyped to verify results.

Table 1. Details of microsatellite markers employed in this study (previously published by Rowe et al., 1997, 2000b) including amplicon size, fluorescent label used with the forward primer, and multiplex assignment.

\begin{tabular}{|c|c|c|c|}
\hline Marker & $\begin{array}{c}\text { Amplicon size } \\
\text { (basepairs) }\end{array}$ & Flourescent label & Multiplex \\
\hline Bcalu1 & $122-138 b p$ & ATTO550 & A \\
\hline Bcalu2 & $179-183 b p$ & FAM & A \\
\hline Bcalu3 & $109-129$ bp & ATTO550 & B \\
\hline Bcalu4 & $188-208 b p$ & FAM & B \\
\hline Bcalu5 & $211-225 b p$ & ATTO550 & $\mathrm{C}$ \\
\hline Bcalu6 & $148-154 b p$ & Yakima Yellow & B \\
\hline Bcalu7 & $139-145 b p$ & Yakima Yellow & A \\
\hline Bcalp10 & $132-144 b p$ & Yakima Yellow & C \\
\hline Bcal $\mu 11$ & $165-193 b p$ & FAM & C \\
\hline
\end{tabular}

\section{Genetic diversity}

Each population and locus was tested for deviation from Hardy-Weinberg equilibrium, null alleles and linkage 
disequilibrium using ARLEQUIN v 3.5.1.3 (Excoffier \& Lischer, 2010); significance was assessed after Bonferroni correction for multiple tests. Loci that were flagged as showing null alleles or had significant linkage disequilibrium in multiple populations were removed from further analyses. Genetic diversity was assessed as allelic richness $\left(A_{R}\right)$, expected heterozygosity $\left(H_{e}\right)$ and observed heterozygosity $\left(\mathrm{H}_{\mathrm{o}}\right)$ using ARLEQUIN v 3.5.1.3 (Excoffier \& Lischer, 2010). Analyses of molecular variance (AMOVA) based on population were run in ARLEQUIN v 3.5.1.3 with 16,000 permutations.

To test for evidence of inbreeding, measured as heterozygote excess within each population, $F_{\text {IS }}$ was calculated using the default parameters within FSTAT $v$ 2.9.4 (Goudet, 1995). The level of heterozygote excess was also determined using the Stepwise Mutation Model (SMM) and the Two-Phase Mutation (TPM) models across the loci in both populations. Sign and Wilcoxon sign-rank tests were conducted in BOTTLENECK $\vee$ 1.2.02 (Piry et al., 1999) using recommended parameter values suitable for microsatellites (proportion of SMM in the TPM $=0.000$ and variance of the geometric distribution for TPM = 0.36). A mode shift indicator test using allele frequency distributions was employed to determine recent bottlenecks.

\section{Population structuring}

Presence of population structuring within each site was tested using STRUCTURE v 2.3.5 (Pritchard et al., 2000). Admixture was assumed and allele frequencies were correlated to 100,000 burn-in cycles and 1,000,000 Markov Chain Monte Carlo runs (following advice from the user manual). The number of potential populations within the sample $(k)$ was considered for $1-10$, with ten replicates per $k$. This was repeated with and without sample origin priors. Results were processed using STRUCTURE HARVESTER v 0.6.8 (Earl \& vonHoldt, 2012), in order to calculate change in the log probability of the data between successive $k$ values (Earl \& vonHoldt, 2012). Likelihood, variance and DK statistics were used to determine the number of genetic clusters present within the dataset. Cluster assignment per individual was plotted using STRUCTURE PLOT v 2 (Ramasamy et al., 2014).

\section{Population trends}

Annual cumulative spawn string count data was extracted from records held by the site managers between 2003 and 2018 or 2019 for Talacre and Red Rocks, respectively. To quantify population trends at each site, generalised linear models with a negative binomial error structure using year as a predictor were fitted to spawn string count, assumed to be related to true population size, from each site. Count effort (survey duration in weeks) was initially used as an additional predictor but this did not improve the fit of models in either case. Additionally, we calculated the relative change in spawn count to indicate trends in population growth. Where $\mathrm{N}$ is the spawn count divided by the survey effort in a given year, relative change in population (y) was defined as follows (Jacobson et al., 2004):

$$
y_{i}=\ln \left(\frac{N_{i+1}}{N}\right)
$$

Trends in relative population change were quantified using simple linear models with year as predictor.

\section{RESULTS}

\section{Genetic diversity}

Thirty-four and 30 samples were collected from Red Rocks and Talacre, respectively, from across the geographic range of each protected area. The alleles for Bcal $\mu 2$ and $B c a l \mu 3$ were fixed in both populations and were removed from further analyses, resulting in seven loci in the final analyses. No linkage disequilibrium was detected between any of the pairs of loci following Bonferroni correction.

All loci showed significant deviation from HardyWeinberg equilibrium in both populations following Bonferroni correction ( $p<0.002)$, except Bcal $\mu 5$ in the Talacre population, which is an indication of non-random mating within populations. Observed heterozygosity was lower than expected heterozygosity at both sites (Red Rocks: $\mathrm{H}_{\mathrm{e}}=0.40 \pm 0.21, \mathrm{H}_{\mathrm{o}}=0.15 \pm 0.20$; Talacre: $\mathrm{H}_{\mathrm{e}}=0.40 \pm 0.21, \mathrm{H}_{\mathrm{o}}=0.12 \pm 0.20$; Table 2) and lower than that previously recorded at the source population around the time that the reintroductions took place $\left(\mathrm{H}_{\mathrm{o}}=\right.$ 0.29; Rowe et al., 1998), suggesting inbreeding has taken place within each site. The occurrence of inbreeding at the reintroduction sites was further confirmed by high $F_{\text {Is }}$ values of 0.43 and 0.72 at Red Rocks and Talacre respectively (Table 2 ). Despite this, allelic richness at the reintroduction sites $(A R=2.71 \pm 1.89$ and $3.43 \pm$ 1.27 at Red Rocks and Talacre, respectively) was in line with that observed at the source population at the time of the reintroduction $\left(A_{R}=2.25\right.$; Rowe et al., 1998) and most molecular variance was found within rather than between sites $($ within $=85.42 \%$; between $=14.58 \%$; $\mathrm{P}<$ 0.01).

Heterozygote excess was not detected in the Red Rocks or Talacre populations under the Stepwise Mutation Model (SMM) or the Two-Phase Mutation Model (TPM) using the Wilcoxon signed-rank test $(p=0.94$ and 0.91 at each site for the two models, respectively) and the sign test (Red Rocks: $p>0.5$ and $>0.2$ and Talacre: $p>0.4$ and $>0.1$ for the two models, respectively). Thus, mutationdrift equilibrium is not rejected for either population (Piry et al., 1999). In line with these results the mode shift indicator test showed a normal L-shaped frequency of heterozygosity for both populations, as expected under mutation-drift equilibrium, giving further evidence that neither population has suffered a bottleneck.

Table 2. Number of samples per site ( $n)$, allelic richness $\left(A_{r}\right)$, expected heterozygosity $\left(\mathrm{H}_{\mathrm{e}}\right)$, observed heterozygosity $\left(H_{0}\right)$, and inbreeding coefficient $\left(F_{1 S}\right)$. Standard deviations $( \pm)$ are indicated for mean values for Red Rocks and Talacre sites. Ainsdale values reproduced from Rowe et al. (1998).

\begin{tabular}{cccccc}
\hline Population & $\boldsymbol{n}$ & $\boldsymbol{A}_{\boldsymbol{r}}$ & $\boldsymbol{H}_{\boldsymbol{e}}$ & $\boldsymbol{H}_{\boldsymbol{o}}$ & $\boldsymbol{F}_{\text {IS }}$ \\
\hline & & & & & \\
Red Rocks & 34 & $2.71 \pm 1.89$ & $0.40 \pm 0.21$ & $0.15 \pm 0.20$ & 0.426 \\
Talacre & 30 & $3.43 \pm 1.27$ & $0.42 \pm 0.22$ & $0.12 \pm 0.20$ & 0.721 \\
Ainsdale & $\sim 40$ & 2.25 & 0.31 & 0.29 & $\mathrm{NA}$ \\
\hline
\end{tabular}



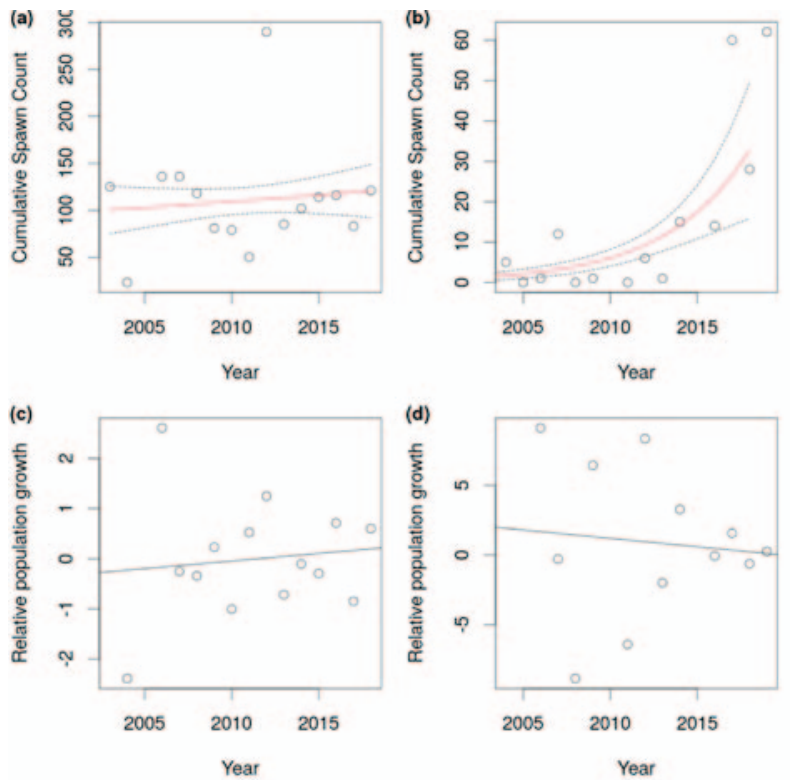

Figure 2. Cumulative spawn counts at (a) Talacre and (b) Red Rocks with red lines indicating population trends fitted using a negative binomial model of spawn count with year as a predictor (standard error indicated by dashed lines) and relative population growth, represented by changes in spawn count, at (c) Talacre and (d) Red Rocks with black lines indicating trends, which do not differ significantly from zero.

\section{Population structuring}

From the Bayesian cluster analysis within each of Red Rocks and Talacre separately, deltaK gave a peak at $\mathrm{K}=$ 2 and the likelihood values peaked at K = 2 (Fig. S1 and S2, Supplementary Materials). However, the STRUCTURE barplots based on $\mathrm{K}=2$ revealed that there was a high level of admixture within the population, which did not support the argument for two sub-populations within each site (Fig. S1 and S2, Supporting Information). It is well documented that the Evanno method cannot definitively identify a $\mathrm{K}$ of 1 (i.e. lack of population structure) (Evanno et al., 2005). Therefore, based on the STRUCTURE barplots (as recommended by Evanno et al., 2005), we postulate that there is no population structure within either of the reintroduced sites (Fig. S1 and S2, Supplementary Materials).

\section{Population trends}

At Talacre, the trend in spawn count (Fig. 2a) did not differ significantly from zero $(\beta=0.01 \pm 0.028, p=0.66)$ whereas spawn counts at Red Rocks (Fig. 2b) were shown to be increasing ( $\beta=0.21 \pm 0.07, p=0.002$ ). There was no significant trend in relative growth at Talacre (Fig. 2c; $\beta=0.03 \pm 0.078, p=0.71$ ) or Red Rocks (Fig. $2 d ; \beta=-0.12$ $\pm 0.39, p=0.76)$.

\section{DISCUSSION}

Inbreeding was observed at both of the reintroduction sites, Red Rocks and Talacre, as evidenced by high $F_{\text {Is }}$ values, low observed compared to expected heterozygosities, and significant deviation from HardyWeinberg equilibrium in the majority of loci at both sites.
Furthermore, observed heterozygosity was lower in the reintroduction sites currently than it was in the source population at the time of the initial reintroductions (Red Rocks: $\mathrm{H}_{\mathrm{o}}=0.15 \pm 0.20$; Talacre: $\mathrm{H}_{\mathrm{o}}=0.12 \pm 0.20$; Ainsdale (source population): $H_{0}=0.29$ (Rowe et al., 1998)). Such low observed heterozygosity values have not previously been recorded in natterjack populations, even for those that are isolated, have a small population size, or are the result of a reintroduction (Rowe et al., 1999, 1998; Frantz et al., 2009; Oromi et al., 2012). However, individuals were not identified and due to multiple site visits, repeat sampling could have taken place, which has the potential to bias diversity estimates downwards (Goldberg \& Waits, 2010). Reduced genetic diversity in reintroduced compared to source populations has previously been observed at two out of five studied natterjack sites in the UK. Rowe et al. (1998) found that $\mathrm{H}_{\mathrm{o}}$ at two translocation sites were 0.18 and 0.16 compared to 0.26 and 0.33 for their source populations, respectively. Loss of genetic diversity is a common consequence of reintroductions as a result of the founder effect, where a small number of individuals are used to seed a new population (Allendorf et al., 2013). Low genetic diversity as a result of population reintroductions has also been observed in a range of other taxa, including birds (Taylor et al., 2017), fish (Thorstensen et al., 2019) and mammals (La Haye et al., 2017). To alleviate this risk, higher numbers and genetic diversity of founder individuals can be introduced, thus increasing genetic diversity in the reintroduced population, which has been linked to reintroduction success in amphibians (Germano \& Bishop, 2009; La Haye et al., 2017).

Despite clear evidence of inbreeding at both sites, values for allelic richness and expected heterozygosity at Red Rocks and Talacre do not differ from those observed at the source population and no evidence of a recent bottleneckwasfound. Geneticbottleneckanalysishas been found to be an accurate indicator of long-term reductions in effective population size in natterjacks over the reintroduction timescale assessed in our study (Beebee \& Rowe, 2001). Indeed, demographic information based on spawn string counts for these sites shows that population numbers have been low in the last ten years and although the population appears to be increasing at Red Rocks, the relative annual growth of both populations is highly variable. The trend in relative growth at both sites did not differ significantly from zero which may be an indication that the populations have grown as large as possible given the habitat available at these sites. Comprehensive monitoring should continue so that this issue might be assessed more fully in the future. Based on the spawn count trend lines, and assuming an equal sex ratio at each site, the current breeding population size is around 200 at Talacre and 70 at Red Rocks, the latter of which is below the population size set as a conservation target for this species of 100 (Denton et al., 1997). Although we did not detect a bottleneck at either site in this study, we cannot rule out the potential that a bottleneck has occurred. Our study non-destructively sampled adults and thus collected data from multiple, overlapping generations, potentially masking the bottleneck effect (Allendorf et al., 2013) whereas the previous study by Beebee \& Rowe (2001) sampled from a single generation using 
larval sampling. Indeed, McEachern et al. (2011) found that a demographically recorded bottleneck in goldenmantled ground squirrels (Spermophilus lateralis) was not detected in genetic signatures due to assumptions of the model: randomly mating, closed populations with nonoverlapping generations, being violated. Further studies on a single larval cohort at these sites could confirm that a bottleneck at the time of the reintroduction is the cause of the observed inbreeding.

Bayesian analysis showed that individuals sampled within each site formed a single admixed population with no restriction to gene flow between breeding pools. This is a positive result as population structuring can lead to lower genetic diversity (Hitchings \& Beebee, 1997; Allendorf et al., 2013). Furthermore, metapopulation dynamics have been identified as important to amphibian persistence in general (Zanini et al., 2009; Griffiths et al., 2010; Bailey \& Muths, 2019) and natterjack survival in particular (Rowe et al., 2000a). Metapopulations allow population persistence and recolonisation following localised extinctions, which is key for species that rely on ephemeral breeding pools, such as natterjacks (Rowe et al., 2000a). Although the lack of within-site population structure demonstrates appropriate habitat management strategies to support movement of individuals within each site, the isolation of both Red Rocks and Talacre from other natterjack sites is of concern. Both sites are surrounded by areas of unsuitable natterjack habitat, with long distances to the next closest natterjack site (Denton et al., 1997). Isolated populations are at a much greater risk of extinction as a result of stochastic processes (Allendorf et al., 2013). This risk is further compounded when populations are small and have low genetic diversity, as they have a lack of resilience to change in environmental conditions (Frankham, 2015).

The natterjack toad reintroduction sites assessed in this study have been identified to be small and isolated with low genetic diversity and are therefore of considerable conservation concern. Low genetic diversity has been linked to reduced fitness in terms of larval growth rates for natterjack toads (Rowe et al., 1999). Rowe et al. (1999) showed that when heterozygosity was lower, larval growth rates were lower; an important fitness trait when developing in ephemeral pools where time available for development may be limited. Our sites had lower heterozygosity than the least genetically diverse population in their study and thus are likely to show severe fitness consequences as a result. Low genetic diversity has also been linked to reduced hatching success in two other pond breeding amphibians (Hynobius tokyoensis and Rana ornativentris) when sites became isolated (Okamiya \& Kusano, 2018). However, low genetic diversity at neutral loci is not an indicator of low diversity at loci under selection, which are key to functionality in relation fitness (Beebee, 2018; Mable, 2019). Therefore, future work to assess levels of adaptive genetic variation in these populations would be interesting in order to understand whether adaptive variation has been maintained despite inbreeding (Mable, 2019).

Inbreeding, leading to inbreeding depression, where a population's ability to survive and reproduce is compromised, leads to a decline in population size
(Allendorf et al., 2013). There are many examples of where inbreeding depression has led to population declines and local extinctions in wild populations (for reviews see Hedrick et al., 2014; Frankham, 2015; Whiteley et al., 2015). The sites in this study do not show a trend for natterjack population decline. However, effects of inbreeding on population growth rates can be hidden in long-lived species, where founders or early generations are still contributing disproportionately to population numbers (Taylor et al., 2017). As the natterjack reintroductions at Red Rocks and Talacre took place around 20 years prior to sampling, and natterjacks have a generation time of 4-5 years (Rowe \& Beebee, 2004), it is possible that the effects of the low genetic diversity have yet to be seen in terms of population declines at these sites. Therefore, it is vital that population monitoring continues at Red Rocks and Talacre and that conservation interventions are developed that will increase genetic diversity.

Genetic rescue is a conservation measure that increases population fitness, seen as demographic growth, as a result of the introduction of novel alleles into a population (Whiteley et al., 2015). Most commonly, genetic rescue is carried out as augmentation of a population using individuals from a closely related/ situated population (Hedrick \& Fredrickson, 2010). Genetic rescue has a number of high-profile conservation success stories, including Florida panther (Puma concolor couguar; Hedrick \& Fredrickson, 2010), greater prairie chicken (Tympanuchus cupido; Westemeier et al., 1998) and adder (Vipera berus; Madsen et al., 1999), and has been suggested to be a widely beneficial but underutilised conservation intervention (Whiteley et al., 2015). There are also some early indications that additional releases at the natterjack reintroduction site in Saltfleetby, on the east coast of the UK, have resulted in increased genetic diversity and population growth at this site, although further monitoring is needed (Beebee, 2014, 2018). The number of translocated individuals does not need to be high to see an increase in fitness in inbred populations (Edmands, 2007; Åkesson et al., 2016;), but introduction of individuals from multiple source sites has been shown to be effective in promoting an increase in genetic diversity even beyond that of the individual source populations themselves (White et al., 2018). However, this must be balanced with the risk of outbreeding depression, where hybrid offspring are less fit than either parent due to the breakdown of locally adapted gene complexes (Edmands, 2007; Sagvik et al., 2005). Indeed, outbreeding depression has been recorded in common frogs (Rana temporaria) when individuals from distant $(130 \mathrm{~km})$ and isolated populations were artificially crossed (Sagvik et al., 2005). Tadpoles resulting from between-population crosses were significantly smaller and more frequently malformed than tadpoles from within-population crosses (Sagvik et al., 2005). The risks of outbreeding depression can be greatly minimised by maximising the genetic and adaptive similarity between source and recipient populations (Edmands, 2007). Therefore, we recommend that small numbers of individuals from multiple sites from the Merseyside dune system, which form a metapopulation with the original source site and have 
high genetic diversity (Rowe et al., 1998), are translocated to the reintroduction sites at Red Rocks and Talacre.

Despite the success of genetic rescue to safeguard small populations, when available habitat cannot support large population sizes, populations are at risk of slipping back into the extinction vortex (Westemeier et al., 1998). This was seen in the greater prairie chicken where, despite genetic rescue attempts, population sizes could not increase beyond the carrying capacity of the environment (Westemeier et al., 1998). It was not until habitat management in conjunction with genetic rescue was carried out that the population of the greater prairie chicken recovered to a stable size (Westemeier et al., 1998). Therefore, genetic rescue at Red Rocks and Talacre will have a greater chance of success if combined with increasing suitable habitat for natterjack toads. As adult population density is directly related to breeding pond density in natterjack toads (Beebee et al., 1996), increasing the number of breeding pools at each site is the most suitable way to increase carrying capacities. Ideally, habitat management would also involve increasing gene flow with other populations through creation of dispersal corridors, to facilitate metapopulation dynamics (Bell et al., 2019). However, the highly isolated nature of the two study sites, which are surrounded by large areas of urban development and unsuitable habitat, means that this is not currently a viable option. Therefore, genetic rescue combined with breeding pool creation for natterjacks at Red Rocks and Talacre, is the most viable option for safeguarding this protected species into the future.

In conclusion, ongoing genetic monitoring is a vital part of informing conservation actions to support, rather than simply assess the success of, reintroduction programmes for protected species. This is particularly important when trends in population growth rates can mask inbreeding in long lived species. Our study has identified two sites where additional conservation intervention is required following reintroduction of a protected species to ensure future survival. Timely genetic assessment in collaboration with conservation organisations can support conservation decisions and promote protected species survival.

\section{ACKNOWLEDGEMENTS}

Thanks to Amphibian and Reptile Conservation and Natural England for granting the licenses to carry out this work and to the landowners, Presthaven Land Ownership, Eni UK Ltd, and Royal Liverpool Golf Club, for permitting access to their sites. Thanks to Mandy Cartwright, Jack Parry, and Cheshire Wildlife Trust volunteers for their assistance with fieldwork and to Lottie Hosie and Trevor Beebee for useful comments on the manuscript. This work was part-funded by an internal grant from the University of Chester.

\section{REFERENCES}

Åkesson, M., Liberg, O., Sand, H., Wabakken, P., Bensch, S. \& Flagstad, $\varnothing$. (2016). Genetic rescue in a severely inbred wolf population. Molecular Ecology 25, 4745-4756.

Allendorf, F.W., Luikart, G. \& Aitken, S.N. (2013). Conservation and the Genetics of Populations: Second Edition. Wiley-
Blackwell, Chichester, UK.

Attard, C.R.M., Möller, L.M., Sasaki, M., Hammer, M.P., Bice, C.M., Brauer, C.J., Carvalho, D.C., Harris, J.O. \& Beheregaray, L.B. (2016). A novel holistic framework for geneticbased captive-breeding and reintroduction programs. Conservation Biology 30, 1060-1069.

Bailey, L.L. \& Muths, E. (2019). Integrating amphibian movement studies across scales better informs conservation decisions. Biological Conservation 236, 261-268.

Beebee, T.J.C. (2014). Amphibian conservation in Britain: A 40year history. Journal of Herpetology 48, 2-12.

Beebee, T.J.C. (2018). Genetic contributions to herpetofauna conservation in the British Isles. Herpetological Journal 28, 51-62.

Beebee, T.J.C. \& Buckley, J. (2014). Natterjack Toad (Bufo calamita) Site Register for the UK 1970 -2009 inclusive.

Beebee, T.J.C., Denton, J.S. \& Buckley, J. (1996). Factors affecting population densities of adult natterjack toads Bufo calamita in Britain. The Journal of Applied Ecology 33, 263.

Beebee, T.J.C. \& Rowe, G. (2001). Application of genetic bottleneck testing to the investigation of amphibian declines: a case study with natterjack toads. Conservation Biology 15, 266-270.

Bell, D.A., Robinson, Z.L., Funk, W.C., Fitzpatrick, S.W., Allendorf, F.W., Tallmon, D.A. \& Whiteley, A.R. (2019). The exciting potential and remaining uncertainties of genetic rescue. Trends in Ecology and Evolution 34, 1070-1079.

Blomqvist, D., Pauliny, A., Larsson, M. \& Flodin, L.Å. (2010). Trapped in the extinction vortex? Strong genetic effects in a declining vertebrate population. BMC Evolutionary Biology 10, 1-9.

Broquet, T., Berset-Braendli, L., Emaresi, G. \& Fumagalli, L. (2007). Buccal swabs allow efficient and reliable microsatellite genotyping in amphibians. Conservation Genetics 8, 509-511.

Cochran-Biederman, J.L., Wyman, K.E., French, W.E. \& Loppnow, G.L. (2015). Identifying correlates of success and failure of native freshwater fish reintroductions. Conservation Biology 29, 175-186.

Corlett, R.T. (2016). Restoration, reintroduction, and rewilding in a changing world. Trends in Ecology and Evolution 31, 453462.

Denton, J.S. \& Beebee, T.J.C. (1992). An evaluation of methods for studying natterjack toads (Bufo calamita) outside the breeding season. Amphibia-Reptilia 13, 365-374.

Denton, J.S., Hitchings, S.P., Beebee, T.J.C. \& Gent, A. (1997). A recovery program for the natterjack toad (Bufo calamita) in Britain. Conservation Biology 11, 1329-1338.

Earl, D.A. \& vonHoldt, B.M. (2012). STRUCTURE HARVESTER: A website and program for visualizing STRUCTURE output and implementing the Evanno method. Conservation Genetics Resources 4, 359-361.

Edmands, S. (2007). Between a rock and a hard place: Evaluating the relative risks of inbreeding and outbreeding for conservation and management. Molecular Ecology 16, 463-475.

Eduardo, A., Nunes, A. \& Brito, D. (2012). Do the protected area network of the State of Minas Gerais maintain viable populations of the lowland Tapir (Tapirus terrestris)? Brazilian Journal of Nature Conservation 10, 27-33.

Evanno, G., Regnaut, S. \& Goudet, J. (2005). Detecting the 
number of clusters of individuals using the software STRUCTURE: A simulation study. Molecular Ecology 14, 2611-2620.

Excoffier, L. \& Lischer, H.E.L. (2010). Arlequin suite ver 3.5: A new series of programs to perform population genetics analyses under Linux and Windows. Molecular Ecology Resources 10, 564-567.

Frankham, R. (2015). Genetic rescue of small inbred populations: meta-analysis reveals large and consistent benefits of gene flow. Molecular Ecology 24, 2610-2618.

Frantz, A.C., Proess, R., Burke, T. \& Schley, L. (2009). A genetic assessment of the two remnant populations of the natterjack toad (Bufo calamita) in Luxembourg. Herpetological Journal 19 53-59.

Germano, J.M. \& Bishop, P.J. (2009). Suitability of amphibians and reptiles for translocation. Conservation Biology 23, 7-15.

Germano, J.M., Field, K.J., Griffiths, R.A., Clulow, S., Foster, J., Harding, G. \& Swaisgood, R.R. (2015). Mitigation-driven translocations: Are we moving wildlife in the right direction? Frontiers in Ecology and the Environment 13, 100-105.

Goldberg, C.S. \& Waits, L.P. (2010). Quantification and reduction of bias from sampling larvae to infer population and landscape genetic structure. Molecular Ecology Resources 10, 304-313.

Goudet, J. (1995). FSTAT (Version 1.2): A computer program to calculate F-Statistics. Journal of Heredity 86, 485-486.

Griffiths, R.A., Sewell, D. \& McCrea, R.S. (2010). Dynamics of a declining amphibian metapopulation: Survival, dispersa and the impact of climate. Biological Conservation 143, 485-491.

Hale, M.L., Burg, T.M. \& Steeves, T.E. (2012). Sampling for microsatellite-based population genetic studies: 25 to 30 individuals per population Is enough to accurately estimate allele frequencies. PLOS ONE. doi: 10.1371/journal. pone. 0045170

Hedrick, P.W. \& Fredrickson, R. (2010). Genetic rescue guidelines with examples from Mexican wolves and Florida panthers. Conservation Genetics 11, 615-626.

Hedrick, P.W., Peterson, R.O., Vucetich, L.M., Adams, J.R. \& Vucetich, J.A. (2014). Genetic rescue in Isle Royale wolves: genetic analysis and the collapse of the population. Conservation Genetics 15, 1111-1121.

Hitchings, S.P. \& Beebee, T.J.C. (1997). Genetic substructuring as a result of barriers to gene flow in urban Rana temporaria (common frog) populations: Implications for biodiversity conservation. Heredity 79, 117-127.

IUCN Species Survival Commission (2013). IUCN Guidelines for reintroductions and other conservation translocations, version 1. Gland, Switzerland.

Jacobson, A.R., Provenzale, A., Von Hardenberg, A., Bassano, B. \& Festa-Bianchet, M. (2004). Climate forcing and density dependence in a mountain ungulate population. Ecology 85, 1598-1610.

La Haye, M.J.J., Reiners, T.E., Raedts, R., Verbist, V. \& Koelewijn, H.P. (2017). Genetic monitoring to evaluate reintroduction attempts of a highly endangered rodent. Conservation Genetics 18, 877-892.

Mable, B.K. (2019). Conservation of adaptive potential and functional diversity: integrating old and new approaches. Conservation Genetics 20, 89-100.
Madsen, T., Shine, R., Olsson, M. \& Wittzell, H. (1999). Restoration of an inbred adder population. Nature 402, 34-35.

McEachern, M.B., Van Vuren, D.H., Floyd, C.H., May, B. \& Eadie, J.M. (2011). Bottlenecks and rescue effects in a fluctuating population of golden-mantled ground squirrels (Spermophilus lateralis). Conservation Genetics 12, 285296

McGrath, A.L. \& Lorenzen, K. (2010). Management history and climate as key factors driving natterjack toad population trends in Britain. Animal Conservation 13, 483-494.

Mims, M.C., Day, C.C., Burkhart, J.J., Fuller, M.R., Hinkle, J., Bearlin, A., Dunham, J.B., DeHaan, P.W., Holden, Z.A. \& Landguth, E.E. (2019). Simulating demography, genetics, and spatially explicit processes to inform reintroduction of a threatened char. Ecosphere 10, 1-24.

Morell, V. (2008). Into the wild: Reintroduced animals face daunting odds. Science 320, 742-743.

Norén, K., Godoy, E., Dalén, L., Meijer, T. \& Angerbjörn, A. (2016). Inbreeding depression in a critically endangered carnivore. Molecular Ecology 25, 3309-3318.

Okamiya, H. \& Kusano, T. (2018). Lower genetic diversity and hatchability in amphibian populations isolated by urbanization. Population Ecology 60, 347-360.

Oromi, N., Richter-Boix, A., Sanuy, D. \& Fibla, J. (2012). Genetic variability in geographic populations of the natterjack toad (Bufo calamita). Ecology and Evolution 2, 2018-2026.

Palomares, F., Godoy, J.A., López-Bao, J.V., Rodríguez, A., Roques, S., Casas-Marce, M., Revilla, E. \& Delibes, M. (2012). Possible extinction vortex for a population of Iberian lynx on the verge of extirpation. Conservation Biology 26, 689697.

Peters, C., Nelson, H., Rusk, B. \& Muir, A.P. (2019). A novel method to optimise the utility of underused moulted plumulaceous feather samples for genetic analysis in bird conservation. Conservation Genetics Resources. doi:10.1007/s12686-019-01117-8

Piry, S., Luikart, G. \& Cornuet, J.-M. (1999). BOTTLENECK: A Computer program for detecting recent reductions in the effective population size using allele frequency data. The Journal of Heredity 90, 502-503.

Pritchard, J.K., Stephens, M. \& Donnelly, P. (2000). Inference of population structure using multilocus genotype data. Genetics and Molecular Research 155, 945-959.

Ramasamy, R.K., Ramasamy, S., Bindroo, B.B. \& Naik, V.G. (2014). STRUCTURE PLOT: A program for drawing elegant STRUCTURE bar plots in user friendly interface. SpringerPlus 3, 1-3.

Robert, A., Colas, B., Guigon, I., Kerbiriou, C., Mihoub, J.B., SaintJalme, M. \& Sarrazin, F. (2015). Defining reintroduction success using IUCN criteria for threatened species: A demographic assessment. Animal Conservation 18, 397406.

Rowe, G. \& Beebee, T.J.C. (2003). Population on the verge of a mutational meltdown? Fitness costs of genetic load for an amphibian in the wild. Evolution 57, 177-181.

Rowe, G. \& Beebee, T.J.C. (2004). Reconciling genetic and demographic estimators of effective population size in the anuran amphibian Bufo calamita. Conservation Genetics 5, 287-298.

Rowe, G., Beebee, T.J.C. \& Burke, T. (1997). PCR primers for polymorphic microsatellite loci in the anuran amphibian 
Bufo calamita. Molecular Ecology 6, 401-402.

Rowe, G., Beebee, T.J.C. \& Burke, T. (1998). Phylogeography of the natterjack toad Bufo calamita in Britain: Genetic differentiation of native and translocated populations. Molecular Ecology 7, 751-760.

Rowe, G., Beebee, T.J.C. \& Burke, T. (1999). Microsatellite heterozygosity, fitness and demography in natterjack toads Bufo calamita. Animal Conservation 2, 85-92.

Rowe, G., Beebee \& T.J.C. \& Burke, T. (2000a). A microsatellite analysis of natterjack toad, Bufo calamita, metapopulations. Oikos 88, 641-651.

Rowe, G., Beebee, T.J.C. \& Burke, T. (2000b). A further four polymorphic microsatellite loci in the natterjack toad Bufo calamita. Conservation Genetics 1, 371-372.

Sagvik, J., Uller, T. \& Olsson, M. (2005). Outbreeding depression in the common frog, Rana temporaria. Conservation Genetics 6, 205-211.

Taylor, G., Canessa, S., Clarke, R.H., Ingwersen, D., Armstrong, D.P., Seddon, P.J. \& Ewen, J.G. (2017). Is reintroduction biology an effective applied science? Trends in Ecology and Evolution 32, 873-880.

Taylor, H.R., Colbourne, R.M., Robertson, H.A., Nelson, N.J., Allendorf, F.W. \& Ramstad, K.M. (2017). Cryptic inbreeding depression in a growing population of a long-lived species. Molecular Ecology 26, 799-813.

Thorstensen, M., Bates, P., Lepla, K. \& Schreier, A. (2019). To breed or not to breed? Maintaining genetic diversity in white sturgeon supplementation programs. Conservation Genetics 20, 997-1007.
Westemeier, R.L., Brawn, J.D., Simpson, S.A., Esker, T.L., Jansen, R.W., Walk, J.W., Kershner, E.L., Bouzat, J.L. \& Paige, K.N. (1998). Tracking the long-term decline and recovery of an isolated population. Science 282, 1695-1698.

White, L.C., Moseby, K.E., Thomson, V.A., Donnellan, S.C. \& Austin, J.J. (2018). Long-term genetic consequences of mammal reintroductions into an Australian conservation reserve. Biological Conservation 219, 1-11.

Whiteley, A.R., Fitzpatrick, S.W., Funk, W.C. \& Tallmon, D.A., (2015). Genetic rescue to the rescue. Trends in Ecology and Evolution 30, 42-49.

Zanini, F., Pellet, J. \& Schmidt, B.R. (2009). The transferability of distribution models across regions: An amphibian case study. Diversity and Distributions 15, 469-480.

\section{Author contributions}

This research was carried out for SP's Masters by Research; she was responsible for all aspects of the work including sampling, molecular work, analyses and writing, supervised by $A M$ and $M G$. AM designed the study and co-wrote the paper. MG contributed to the statistical analyses. MA, SB and KN contributed to study design and collected the samples. RB and $\mathrm{KP}$ contributed to the molecular work. All authors contributed to editorial content.

\section{Data accessibility}

Sample locations and microsatellite data: https://figshare.com/ articles/Microsatellite_data_and_sampling_locations/12546242

Accepted: 30 May 2020

\section{Please note that the Supplementary Materials are available via the Herpetological Journal website: https://thebhs.org/publications/the-herpetological-journal/volume-30-number3-july-2020}

